\title{
Modular Approach to Launch Vehicle Design Based on a Common Core Element
}

\author{
Dennis M. Creech ${ }^{1}$ \\ Jacobs Engineering - Jacobs, ESTS Group, Huntsville, AL, 35806, United States \\ Grady E. Threet, Jr. ${ }^{2}$ and Alan D. Philips ${ }^{3}$ \\ NASA, George C. Marshall Space Flight Center, AL, 35812, United States \\ Eric D.Waters ${ }^{4}$ \\ Dynamic Concepts Inc - Jacobs, ESTS Group, Huntsville, AL, 35806, United States \\ Mike Baysinger ${ }^{5}$ \\ Qualis Corporation - Jacobs, ESTS Group, Huntsville, AL, 35805, United States
}

\begin{abstract}
With a heavy lift launch vehicle as the centerpiece of our nation's next exploration architecture's infrastructure, the Advanced Concepts Office at NASA's Marshall Space Flight Center initiated a study to examine the utilization of elements derived from a heavy lift launch vehicle for other potential launch vehicle applications. The premise of this study is to take a vehicle concept, which has been optimized for Lunar Exploration, and utilize the core stage with other existing or near existing stages and boosters to determine lift capabilities for alternative missions. This approach not only yields a vehicle matrix with a wide array of capabilities, but also produces an evolutionary pathway to a vehicle family based on a minimum development and production cost approach to a launch vehicle system architecture, instead of a purely performance driven approach. The upper stages and solid rocket booster selected for this study were chosen to reflect a cross-section of: modified existing assets in the form of a modified Delta IV upper stage and Castor-type boosters; potential near term launch vehicle component designs including an Ares I upper stage and 5segment boosters; and longer lead vehicle components such as a Shuttle External Tank diameter upper stage. The results of this approach to a modular launch system are given in this paper.
\end{abstract}

\section{Introduction}

$\mathrm{T}$ he Advanced Concepts Office (ACO) at NASA Marshall Space Flight Center has analyzed over 2000 heavy lift concepts in the last three years. These concepts were evaluated for a variety of studies with a focus on Lunar Exploration Missions, heavy lift capability to Low Earth Orbit (LEO), exploratory missions to Near Earth Objects (NEO) in our solar system, and various hyperbolic escape velocity squared (C3) values. The vehicle concept analyses that ACO produce have generally been optimized to deliver the maximum payload capability to the desired orbit and are strictly performance driven. With the pending retirement of the shuttle fleet, our nation will be without a civil heavy lift launch capability. The development of a new heavy lift vehicle is imperative for the exploration and large science missions our Agency has been tasked to deliver.

A core stage from a heavy lift launch vehicle that was designed to withstand the loads and environments of a lunar exploration mission was chosen to be the modular common element for the vehicles selected for this study.

\footnotetext{
${ }^{1}$ Aerospace Engineer, Advanced Concepts Office, George C. Marshall Space Flight Center/ED04, AIAA Senior Member.

${ }^{2}$ Lead Aerospace Engineer, Advanced Concepts Office, George C. Marshall Space Flight Center /ED04.

${ }^{3}$ Aerospace Engineer, Advanced Concepts Office, George C. Marshall Space Flight Center/ED04.

${ }^{4}$ Engineer/Scientist, Advanced Concepts Office, George C. Marshall Space Flight Center/ED04, AIAA Student Member.

${ }^{5}$ Design Engineer, Advanced Concepts Office, George C. Marshall Space Flight Center/ED04.
} 
The lighter payload class vehicle concepts of this family would carry structural penalties for scarring for the heavier payload vehicles and thus would be un-optimized for performance due to these constraints. Since cost and reliability analyses were not performed during this study, a subjective assessment of vehicle concept feasibility was made after the performance was determined for each option. Once this was determined, a phased development approach could be employed for the family of viable concepts.

\section{Study Methodology}

\section{A. Ground Rules and Assumptions (GR\&A)}

This study followed the GR\&A produced and utilized for the NASA Heavy Lift Launch Vehicle (HLLV) Architecture study of 2009. Some of these are particularly influential to the study results:

1) Vehicle Assembly Building (VAB) launch vehicle stack integrated height constraint $=390 \mathrm{ft}$

2) Thrust-to-weight at liftoff $\geq 1.2$

3) All structural and payload shroud designs use Al-Li 2195

4) Acceleration constraints: $5 \mathrm{~g}$ limit for cargo missions versus $4 \mathrm{~g}$ limit for crewed missions

5) Maximum dynamic pressure (q) not to exceed $800 \mathrm{psf}$

6) Payload shroud jettison when 3-sigma Free Molecular Heating Rate $\leq 0.1 \mathrm{BTU} / \mathrm{ft}^{2}$-s

\section{B. ACO Launch Vehicle Design Tools}

INTegrated ROcket Sizing (INTROS) is an analytical tool that was developed at MSFC to facilitate launch vehicle design and sizing. Written in Visual Basic for Applications, INTROS assists the engineer in four basic tasks: vehicle architecture, launch vehicle sizing, technology and system trade studies, and parameter sensitivity studies. ${ }^{1}$ Launch vehicle design and sizing are based on stage geometry and mass properties. Mass properties are established from a large master list of launch vehicle systems, subsystems, propellants and fluids. Mass calculations are based on Mass Estimating Relationships (MERs) that are automatically generated from a large database that is built into the program. Program mass calculation accuracy for existing and historical launch vehicles has been verified to be well within $5 \%$.

Launch Vehicle Analysis (LVA) is a standalone application written at MSFC in Visual Basic that provides quick turnaround launch vehicle structural design and analysis. An important note, this program does not use weight estimating or scaling routines, but supplies detailed analysis by using time proven engineering methods based on material properties, load factors, aerodynamic loads, stress, elastic stability, deflection, etc. For the fastest turnaround, the program is designed to work with the absolute minimum of input data. The output data is purposely limited to the least possible quantity to prevent the analyst from having to dig through a large amount of data for the necessary information. LVA and its predecessors have been serving NASA for over 25 years. Maximum dynamic pressure and acceleration are run as the maximum for the class of vehicle. Loads are run as a single combined worst case.

Program to Optimize Simulated Trajectories (POST3D) is a FORTRAN 77 based legacy code developed by NASA Langley for detailed trajectory simulations.

POST is a generalized point mass, discrete parameter targeting and optimization program. POST provides the capability to target and optimize point mass trajectories for a powered or unpowered vehicle near an arbitrary rotating, oblate planet. POST has been used successfully to solve a wide variety of atmospheric ascent and reentry problems, as well as exo-atmospheric orbital transfer problems. The generality of the program is evidenced by its N-phase simulation capability which features generalized planet and vehicle models. This flexible simulation capability is augmented by an efficient discrete parameter optimization capability that includes equality and inequality constraints. ${ }^{2}$

\section{ACO Launch Vehicle Performance and Sizing Process}

The process used for the preliminary performance and sizing of the launch vehicle and EDS concepts is shown in Fig. 1. Based upon the mission requirements for the particular concept under study and within the framework of the ground rules and assumptions established, a preliminary concept is sized using the MERs in INTROS. An initial trajectory of this vehicle is flown in POST to determine the ascent flight environments (accelerations, dynamic pressure, payload capability, etc.) and then the initial vehicle weights and trajectory outputs are sent for more detailed structural sizing by LVA. Loads, forces, material properties, and design techniques are all considered within the LVA analysis and new structural weights are calculated for the launch vehicle or Earth Departure Stage (EDS) concept. INTROS then incorporates these new structural element weights and estimates a total injected mass based on the total ideal delta velocity from the previous POST output. POST then determines a new total injected mass and ideal delta velocity. INTROS takes these values from POST and estimates a new propellant load and stage mass and 
continues to iterate with POST until the POST total injected mass is within $0 \mathrm{lbm}$ to $300 \mathrm{lbm}$ of the INTROS estimated value. If at any time during the iteration process the max q or max g strays beyond a nominal value, the LVA analysis is repeated. The performance and sizing analysis for this concept is then considered closed and a vehicle summary is generated.

If a cost analysis of the concept is to be performed, the vehicle configuration description and mass summary for the vehicle and its elements are then sent to the cost team. Likewise, if a reliability analysis is to be performed, the vehicle configuration description and closed case trajectory summary are sent to the reliability team. For the vehicles described in this report, cost and reliability analyses were not requested.

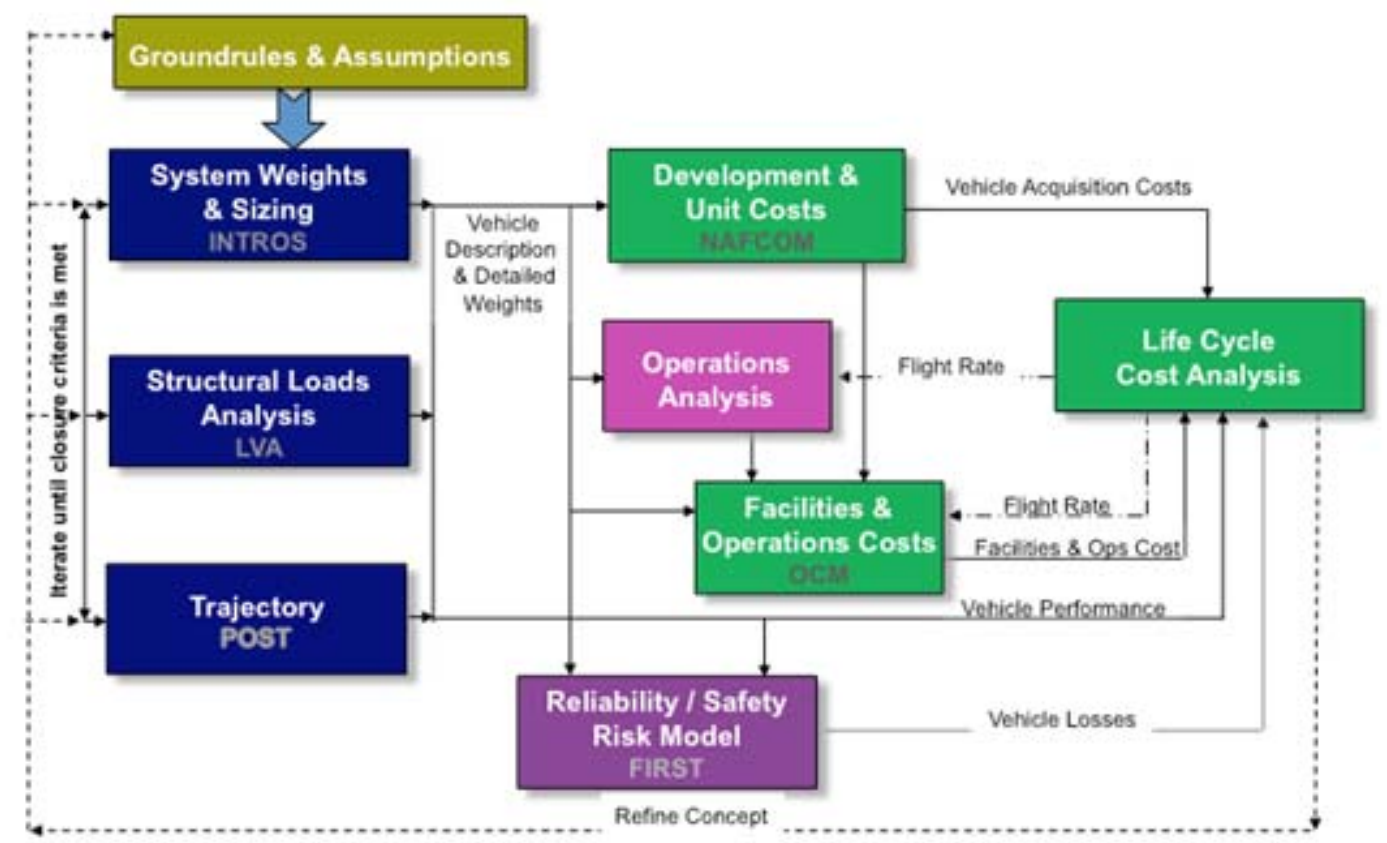

Processes can be adjusted if necessary

Figure 1. ACO concept design process.

\section{Study Specific Processes}

In addition to following the ACO standard practices outlined above, several additional tasks unique to this particular study were carried out. Typical, individual vehicle studies rely upon a single LVA output per concept, as aerodynamic loads and vehicle size are usually well understood. This study was atypical in that the common core stage had to be structurally designed such that all loads encountered from the various boosters and upper stages were considered. Accomplishing this meant that all concept vehicle sizes and trajectories had to be initially characterized. Once this was complete, the LVA operator analyzed each concept on an individual basis. Then, output masses for each concept had to be compared on a piece-parts basis to every other concept in the study matrix. This type of matrix-wide assessment allowed for the determination of the most robust parts of each concept, resulting in the application of these parts to all concepts, creating a structurally common core stage able to support the maximum range of loads. Incidentally, this approach did not yield a weight optimized core for each individual concept. An example of this analysis process with results is given in the Structural Analysis section. 


\section{Vehicle Concept Elements and Configurations}

The process for this study began with the initial INTROS modeling of each vehicle configuration in the desired final matrix. Each concept included in the final matrix makes use of a common core element and several add-on elements (Fig. 2). These are combined in such a fashion to support an evolutionary development process as well as cover a wide array of performance capabilities. The following outlines all vehicle stack constituents utilized.

\section{A. Common Core Element}

The core stage utilized in this study began as an element of a vehicle concept resultant from a 2009 NASA study (98.24.00). It has a diameter equivalent to that of the Shuttle External Tank (ET) at $27.6 \mathrm{ft}$ (331 in) and is $213 \mathrm{ft}$ tall, nozzle exit to forward skirt. The aftmounted fuel tank is capable of holding $318,500 \mathrm{lbm}$ of useable Liquid Hydrogen (LH2) and has been sized such that the thrust beam of the 5-segment SRB's, when utilized, passes above with an acceptable margin. The forward mounted oxidizer tank can hold $1.89 \mathrm{M} \mathrm{lbm}$ of useable Liquid Oxygen (LOX) and is sized using the mixture ratio of the given engines in reference to a fully loaded fuel tank. Note that LOX tank sizing does factor in the oxidizer held in the feedlines of the Main Propulsion System (MPS). The dry mass, with growth margin, of this common core is $247,500 \mathrm{lbm}$ and structures are Al-Li 2195 exclusively. The dry mass increases slightly for those concepts not using SRB's due to hold down equipment. Propelling this stage are five RS-25-E engines, which are the expendable variant of the Space Shuttle Main Engine (SSME).All vehicle concepts detailed make use of this particular core.

\section{B. 5-Segment PBAN SRB}

The SRB used in this study is the same as used with the Ares I vehicle and was also baselined with the Ares V concept. It is a steel-case, recoverable booster with Polybutadiene acrylonitrile (PBAN) propellant and an Ares I trace flown with $1 \%$ thrust degradation at $61^{\circ} \mathrm{F}$ Propellant Mean Bulk Temperature (PMBT). Nozzle to tip the $\mathrm{SRB}$ is $177 \mathrm{ft}$ in length. Each booster has a gross mass of $1.6 \mathrm{M} \mathrm{lbm}$ and $3.5 \mathrm{M} \mathrm{lbf}$ of vacuum thrust.

\section{Castor-120 type SRM}

A smaller solid motor booster utilized on several concepts, it is similar in type and performance to the ATK Castor 120. With a length of $29.6 \mathrm{ft}$ and a diameter of $7.7 \mathrm{ft}$ the composite case holds approximately 108,000 lbm of propellant and has a gross mass of $117,000 \mathrm{lbm}$. The boosters have an average thrust of 370,930 lbf and are grouped in fours for the respective concepts.

\section{Modified DIV Upper Stage}

This is a modified upper stage element derived from a Delta IV vehicle. The stage is roughly $38 \mathrm{ft}$ in length, nozzle to forward skirt, and has a diameter of $16.4 \mathrm{ft}(5 \mathrm{~m})$. The fuel tank holds $8,200 \mathrm{lbm}$ of useable LH2 and the oxidizer tank can contain 48,000 lbm of useable LOX. Dry mass of the stage is $9,500 \mathrm{lbm}$. Structural masses have been impacted from the common core analysis procedure, yet dimensions are virtually unchanged from the existing stage. A single RL-10B2 engine is utilized.

\section{E. Ares I Upper Stage}

Another element applied to the common core is the Ares I upper stage. This is the upper element designed to fly atop the 5-segment SRB first stage of the Ares I. Nozzle to forward skirt length is $89 \mathrm{ft}$ and diameter is $18 \mathrm{ft}(5 \mathrm{~m})$. Nested propellant tanks enable similar capacity with less length than conventionally domed vessels with intertank 
structures. In this configuration the fuel tank can hold 45,800 lbm of useable LH2 and the oxidizer tank has a capacity of $250,600 \mathrm{lbm}$ of useable LOX. Structures utilize composite elements and dry mass is $44,000 \mathrm{lbm}$. Like the DIV upper stage, there was no resizing done relative to the original design, yet masses have been affected by the process of the study. For example, this particular stage had to support payloads and flight loads which fell out of the original design scope, creating the need for supplemental structural mass. The stage is powered by a single J-2X engine.

\section{F. ET Diameter Upper Stage}

This upper stage has the same diameter as the common core at $27.6 \mathrm{ft}$ and is $63 \mathrm{ft}$ in length. Unlike the Ares I upper stage, the tanks are dual dome separated by an intertank. The propellant load was optimized for LEO payload delivery. Similar to the Ares I upper stage, the fuel tank can hold up to 45,800 lbm of useable LH2 and the oxidizer tank contains up to $250,600 \mathrm{lbm}$ of useable LOX. Dry mass of the stage is $40,500 \mathrm{lbm}$ and it is powered by a single $\mathrm{J}-2 \mathrm{X}$ engine.

\section{G. Crew Exploration Vehicle (CEV) / Launch Abort System (LAS)}

The CEV's flown on several of these vehicles are generic versions of the Orion-type capsule systems. The LAS is held at a constant mass of $16,500 \mathrm{lbm}$, whereas the CEV system mass is allowed to float in accordance with the performance of the vehicle to the particular orbit. Specifically, the mass of the capsule for each respective concept flying to International Space Station (ISS) may not exceed the quoted payload performance. A point of reference can be made, when reviewing results, by noting the current Orion CEV mass is in the realm of $20 \mathrm{t}$. For this study all CEV concepts are inserted into an initial orbit of -11 x $100 \mathrm{nmi} @ 51.6^{\circ}$ prior to ISS orbital transfer.

\section{H. Payload Shrouds}

Cargo missions were inserted into a LEO delivery orbit of $30 \mathrm{nmi}$ x $130 \mathrm{nmi} @ 29^{\circ}$ and respective shrouds were sized based upon concept height and payload capability. All shrouds are bi-conic, utilize Al-Li 2195 and were structurally analyzed via LVA. Dimensions reference the cylindrical portion of the shroud, which ACO reports as the payload envelope.

1) No upper stage: $27.6 \mathrm{ft} \times 80.0 \mathrm{ft}$

2) DIV upper stage: $18.1 \mathrm{ft}(5.5 \mathrm{~m}) \times 60.0 \mathrm{ft}$ hammerhead from $16.0 \mathrm{ft}(5.0 \mathrm{~m})$ DIV diameter

3) Ares I upper stage: $21.3 \mathrm{ft}(6.5 \mathrm{~m}) \times 60.4 \mathrm{ft}$ hammerhead from $18.1 \mathrm{ft}(5.5 \mathrm{~m})$ Ares I diameter

4) ET diameter upper stage: $27.6 \mathrm{ft} \times 80.0 \mathrm{ft}$

The utilization of common shrouds on multiple launch vehicle concepts was desired. Widely varying payload densities prevented matching shroud dimensions on the DIV and Ares I upper stage concepts; however, the $27.6 \mathrm{ft}$ diameter shroud was utilized across multiple concept configurations.

\section{Vehicle Concept Matrix}

All vehicle concepts analyzed, with respective elements and mission orbits, are listed in Table 1 . The vehicle identification numbers are functions of the ACO internal numbering scheme and are for classification only. An illustration of these vehicles is given in Fig. 3. 
Table 1. Concept Vehicle Matrix.

\begin{tabular}{|c|c|c|c|c|c|}
\hline ID & Booster & Core & Upper Stage & $\begin{array}{l}\text { Payload } \\
\text { Element }\end{array}$ & Mission \\
\hline 108.00 .00 & (2) 5-seg SRB & (5) RS-25E & - & CEV/Cargo & ISS $(-11 \times 100 \mathrm{nmi})$ \\
\hline 108.00 .01 & (2) 5-seg SRB & (5) RS-25E & - & Cargo shroud & LEO $(30 \times 130 \mathrm{nmi})$ \\
\hline 108.00 .02 & (4) Castor-120 & (5) RS-25E & - & Cargo shroud & LEO $(30 \times 130 \mathrm{nmi})$ \\
\hline 108.01 .00 & - & (5) RS-25E & DIV RL-10B-2 & CEV & ISS $(-11 \times 100 \mathrm{nmi})$ \\
\hline 108.01 .01 & (4) Castor-120 & (5) RS-25E & DIV RL-10B-2 & Cargo shroud & LEO $(30 \times 130 \mathrm{nmi})$ \\
\hline 108.02 .00 & - & (5) RS-25E & Ares1 (1) J-2X & CEV & ISS $(-11 \times 100 \mathrm{nmi})$ \\
\hline 108.02 .01 & (4) Castor-120 & (5) RS-25E & Ares1 (1) J-2X & Cargo shroud & $\operatorname{LEO}(30 \times 130 \mathrm{nmi})$ \\
\hline 108.02 .02 & (2) 5-seg SRB & (5) RS-25E & Ares1 (1) J-2X & Cargo shroud & LEO $(30 \times 130 \mathrm{nmi})$ \\
\hline 108.03 .00 & - & (5) RS-25E & (1) $\mathrm{J}-2 \mathrm{X}$ & CEV & ISS (-11 x $100 \mathrm{nmi})$ \\
\hline 108.03 .01 & (2) 5-seg SRB & (5) RS-25E & (1) $\mathrm{J}-2 \mathrm{X}$ & Cargo shroud & $\operatorname{LEO}(30 \times 130 \mathrm{nmi})$ \\
\hline
\end{tabular}

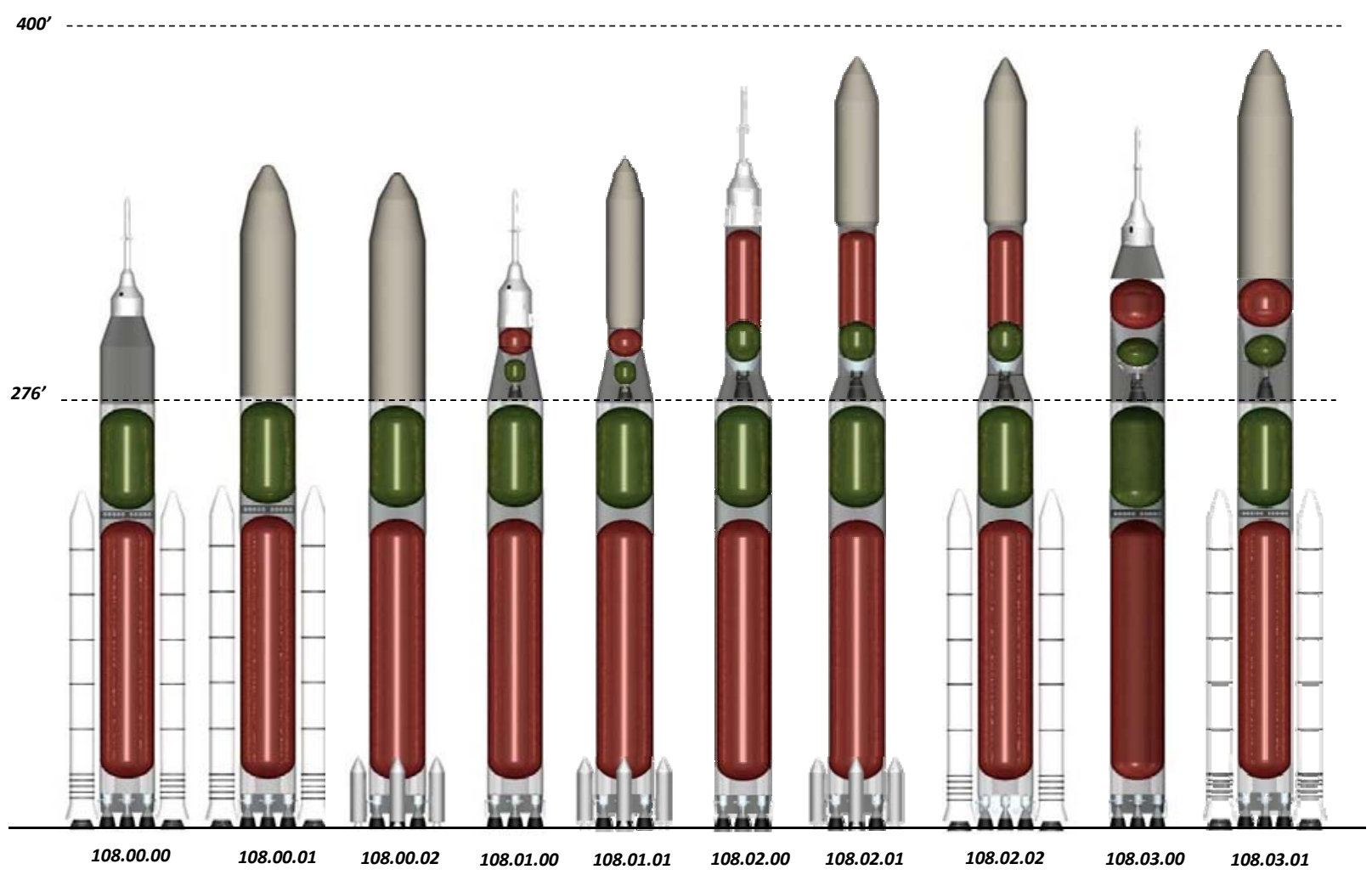

Figure 3. Concept vehicles analyzed. 


\section{Structural Analysis}

The use of launch vehicle main structural components on more than one configuration is a concept that has a significant amount of desirable qualities. However, it also has several drawbacks. Mainly, the structural components must be sized for all loading conditions that it will experience and the extra weight from the highly loaded configurations will also be carried by the lightly loaded configurations. Hopefully, the desirable qualities will outweigh the undesirable ones.

As an example the LVA analysis of two configurations will be presented: vehicle 108.00 .01 (Fig. 4) and vehicle 108.03.01 (Fig. 5). Vehicle 108.00.01 is an ET diameter core with RS-25E engines, 5-segment SRB's, and a payload shroud. The 108.03.01 is similar to the previous concept except that it also has an upper stage on top of the core.

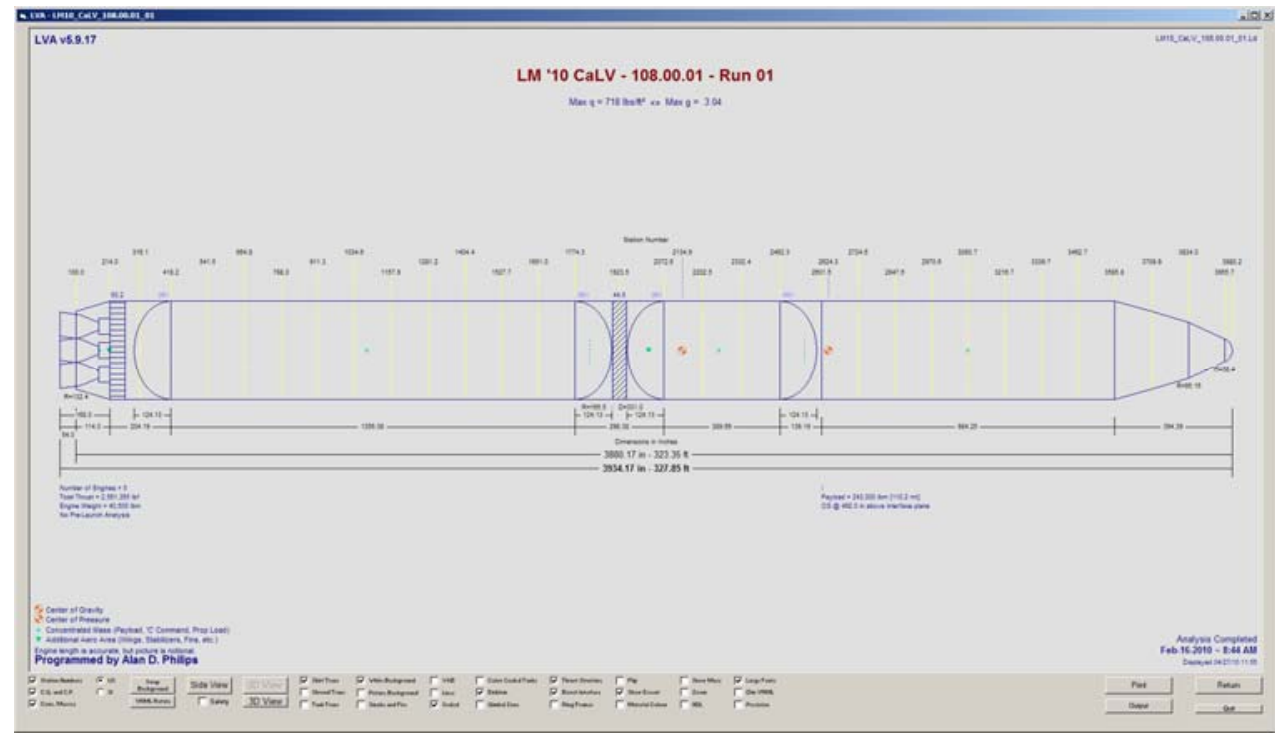

Figure 4. 108.00.01 configuration.

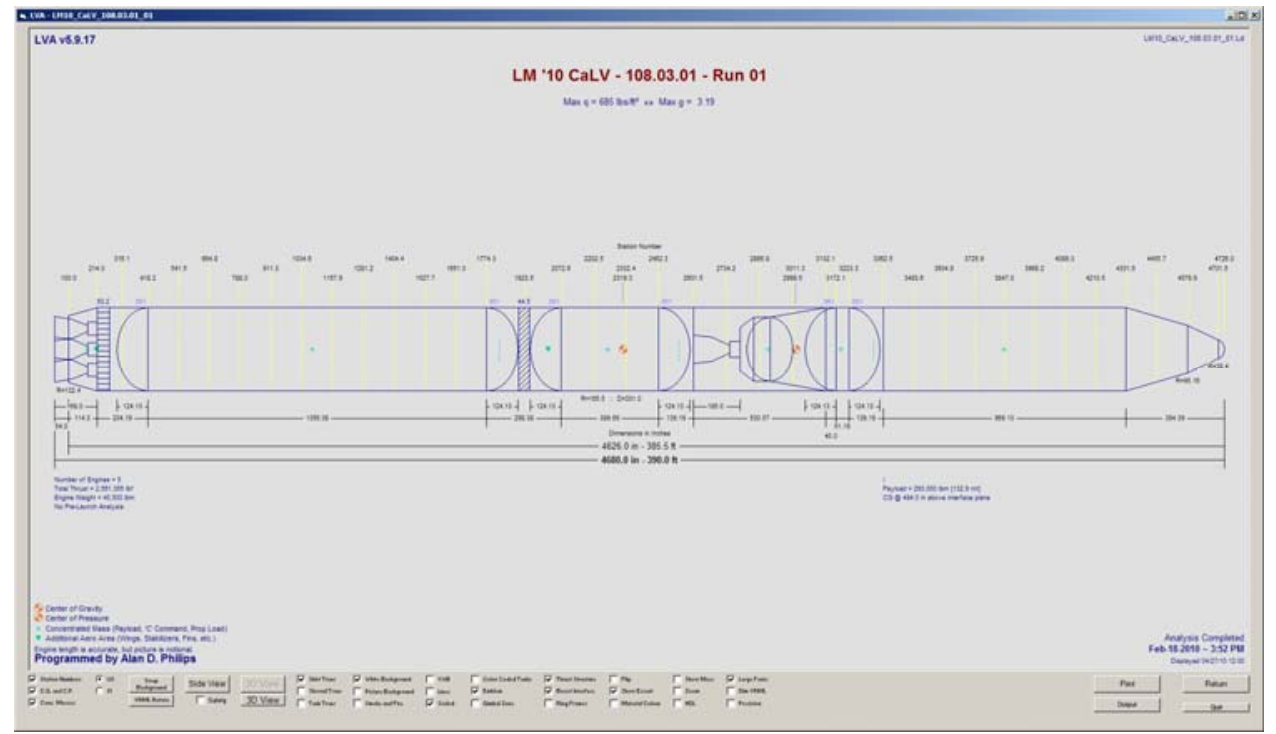

Figure 5. 108.03.01 configuration.

Starting from a textual descriptive input file, the program executes a pre-launch and flight loads analysis and translates it into an accurate structural weight estimate. LVA uses proven direct solution techniques as provided by 
the NASA Astronautics Structures Manual and the McDonnell Douglas Isogrid Design Handbook to do the analysis and generate the weight estimates. LVA generally takes less than one minute to perform an iterative loads and structural analysis. LVA's outputs include a detailed structural weight statement including sizing parameters, a toscale dimensioned drawing, a calculated loads graph, and a to-scale 3D rotatable configuration illustration.

Table 2. Loads Comparison.

\begin{tabular}{|c|c|}
\hline Vehicle 108.00.01 & Vehicle 108.03.01 \\
\hline Shorter vehicle: less bending moment & Longer vehicle: more bending moment \\
\hline Lighter vehicle: higher max dynamic pressure (q) & Heavier vehicle: lower max q \\
\hline Lighter vehicle: higher lift-off acceleration (g) & Heavier vehicle: lower lift-off g \\
\hline No second stage: lower flight g & Second stage: higher flight g \\
\hline
\end{tabular}

As illustrated in Fig. 6 and Fig. 7, it's a bit of a mixed bag in reference to the loads. Some loads are higher on one vehicle while other loads are higher on the second vehicle.

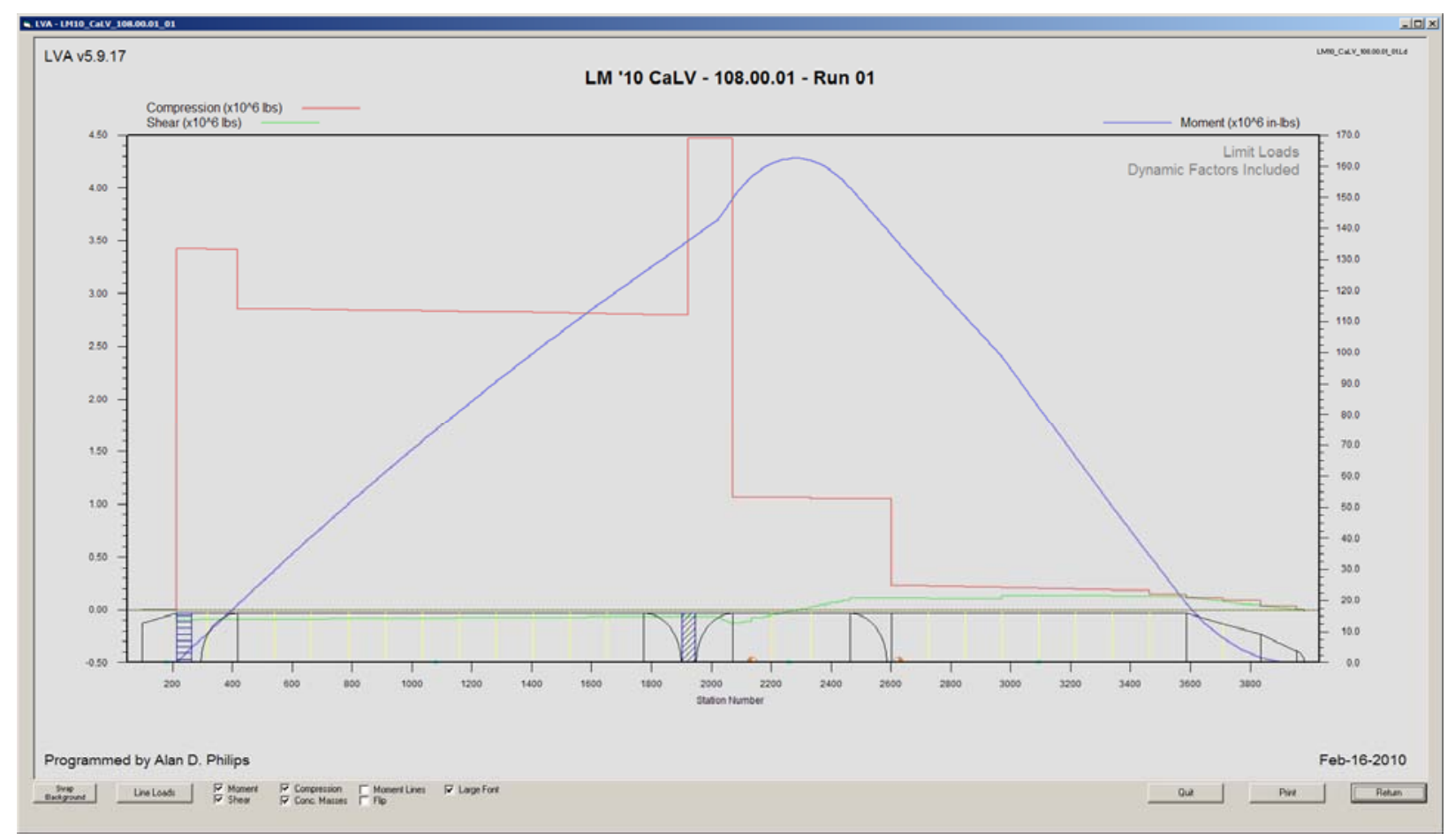

Figure 6. 108.00.01 structural loads. 


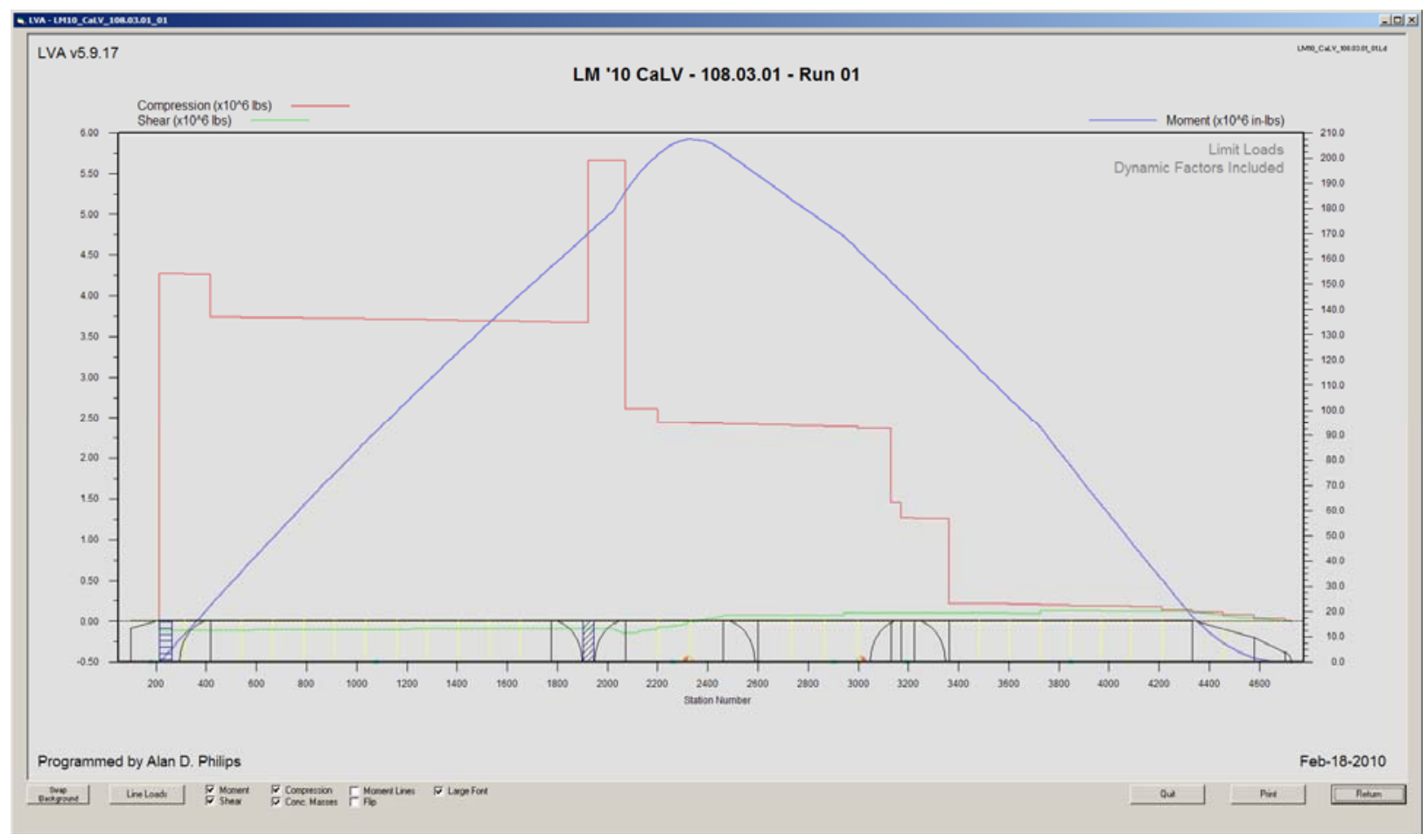

Figure 7. 108.03.01 structural loads.

The bending moment (triangular shaped line) for vehicle 108.00.01 peaks at about 160 million inch pounds while the bending moment for vehicle 108.03 .01 peaks at nearly 210 million inch pounds. Also, the compression load (step function line) reaches about 4.5 million pounds for vehicle 108.00.01 while the compression load reaches nearly 5.75 million pounds for vehicle 108.03 .01 . Vehicle 108.03 .01 will clearly be the weight driver as it has the highest loads.

Table 3. Concept vehicle's itemized weights.

\begin{tabular}{r|r|r|r|}
\cline { 2 - 4 } & $\begin{array}{c}\mathbf{1 0 8 . 0 0 . 0 1} \\
\text { (lbs) }\end{array}$ & $\begin{array}{c}\mathbf{1 0 8 . 0 3 . 0 1} \\
\text { (lbs) }\end{array}$ & \multicolumn{1}{c|}{$\begin{array}{c}\text { Common } \\
\text { (lbs) }\end{array}$} \\
\cline { 2 - 4 } Fwd Skirt & 2895.1 & 3717.6 & 3717.6 \\
LOX Tank & 18357.3 & 18689.9 & 18689.9 \\
Intertank & 13691.9 & 15493.5 & 15493.5 \\
LH2 Tank & 39565.1 & 41456.9 & 41456.9 \\
Aft Skirt & 4810.3 & 5336.1 & 5336.1 \\
Eng Comp & 1200.3 & 1188.4 & 1200.3 \\
\cline { 2 - 4 } Total & 80520.0 & 85882.4 & $\mathbf{8 5 8 9 4 . 3}$ \\
\cline { 2 - 4 } & & &
\end{tabular}

As expected, vehicle 108.03.01 completely drove the weights (Table 3). The sole holdout was the engine compartment, which had a higher weight in vehicle 108.00.01 due to the higher max q. When placing the common core into vehicle 108.00.01, the core weight increases by over $5000 \mathrm{lbm}$, which will have a significant effect on the payload carrying capability. 


\section{Performance Results and Observations}

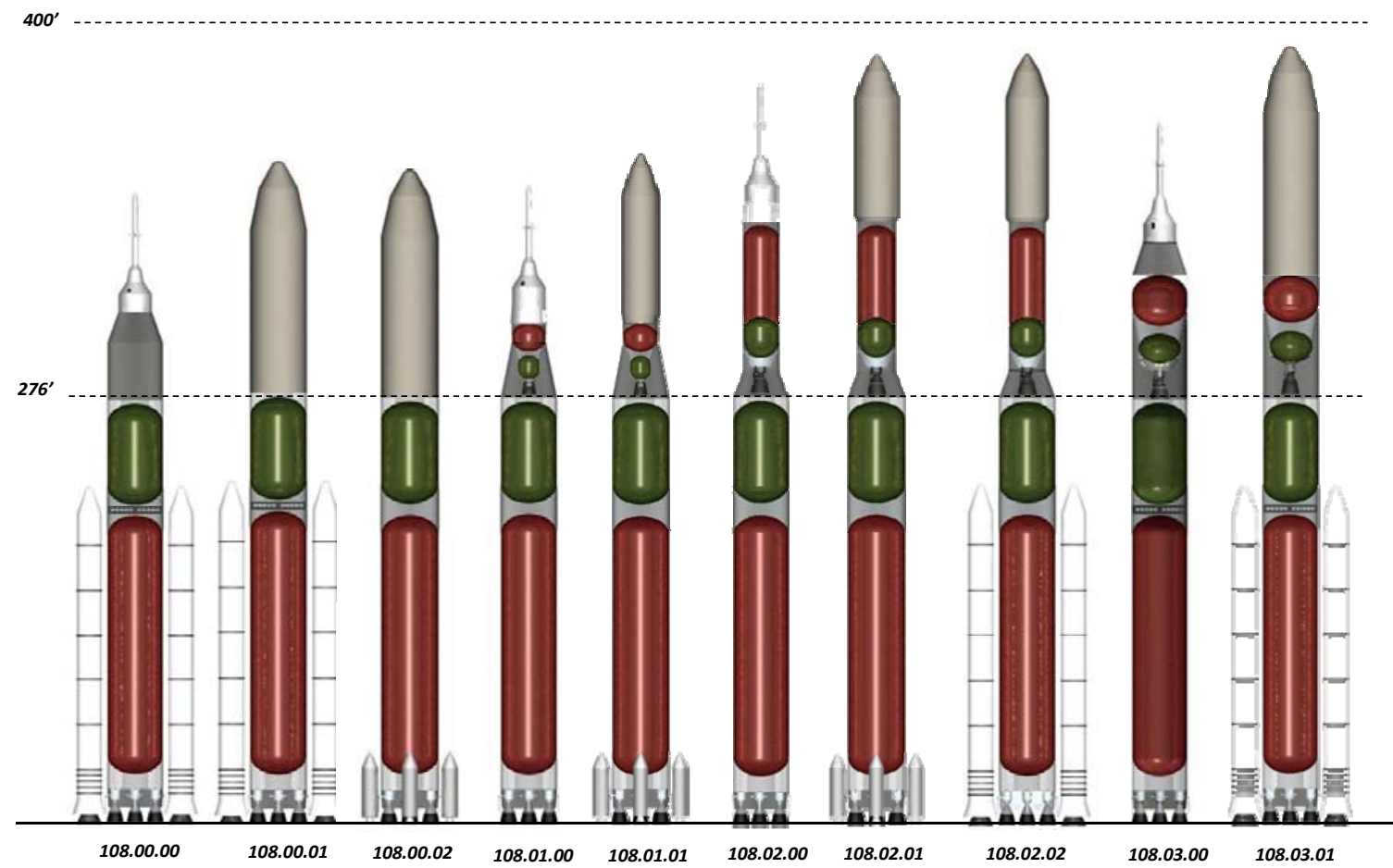

\begin{tabular}{c|c|c|c|c|c|c|c|c|c|c} 
Core Stage & 5 RS-25 & 5 RS-25 & 5 RS-25 & 5 RS-25 & 5 RS-25 & 5 RS-25 & 5 RS-25 & 5 RS-25 & 5 RS-25 & 5 RS-25 \\
\hline Booster Type & 5-seg SRB & 5-seg SRB & $\begin{array}{c}4-C a s t o r \\
120\end{array}$ & N/A & $\begin{array}{c}4-C a s t o r \\
120\end{array}$ & N/A & $\begin{array}{c}\text { 4-Castor } \\
120\end{array}$ & 5 -seg SRB & N/A & 5 -seg SRB \\
\hline Upper Stage & N/A & N/A & N/A & $\begin{array}{c}\text { Delta IV } \\
\text { RL-10 B2 }\end{array}$ & $\begin{array}{c}\text { Delta IV } \\
\text { RL-10 B2 }\end{array}$ & $\begin{array}{c}\text { Ares I } \\
\text { J-2X }\end{array}$ & $\begin{array}{c}\text { Ares I } \\
\text { J-2X }\end{array}$ & $\begin{array}{c}\text { Ares I } \\
\text { J-2X }\end{array}$ & $\begin{array}{c}\text { ET Dia } \\
\text { J-2X }\end{array}$ & $\begin{array}{c}\text { ET Dia } \\
\text { J-2X }\end{array}$ \\
\hline Payload Capacity (t) & 83.1 & 89.1 & 11.9 & 13.2 & 42.3 & 25.1 & 57.7 & 122.8 & 23.2 & 120.7 \\
\hline Mission Orbit & $\begin{array}{c}\text { ISS } \\
\text { Transfer }\end{array}$ & LEO & LEO & $\begin{array}{c}\text { ISS } \\
\text { Transfer }\end{array}$ & LEO & $\begin{array}{c}\text { ISS } \\
\text { Transfer }\end{array}$ & LEO & LEO & $\begin{array}{c}\text { ISS } \\
\text { Transfer }\end{array}$ & LEO
\end{tabular}

Figure 8. Concept analysis results. 


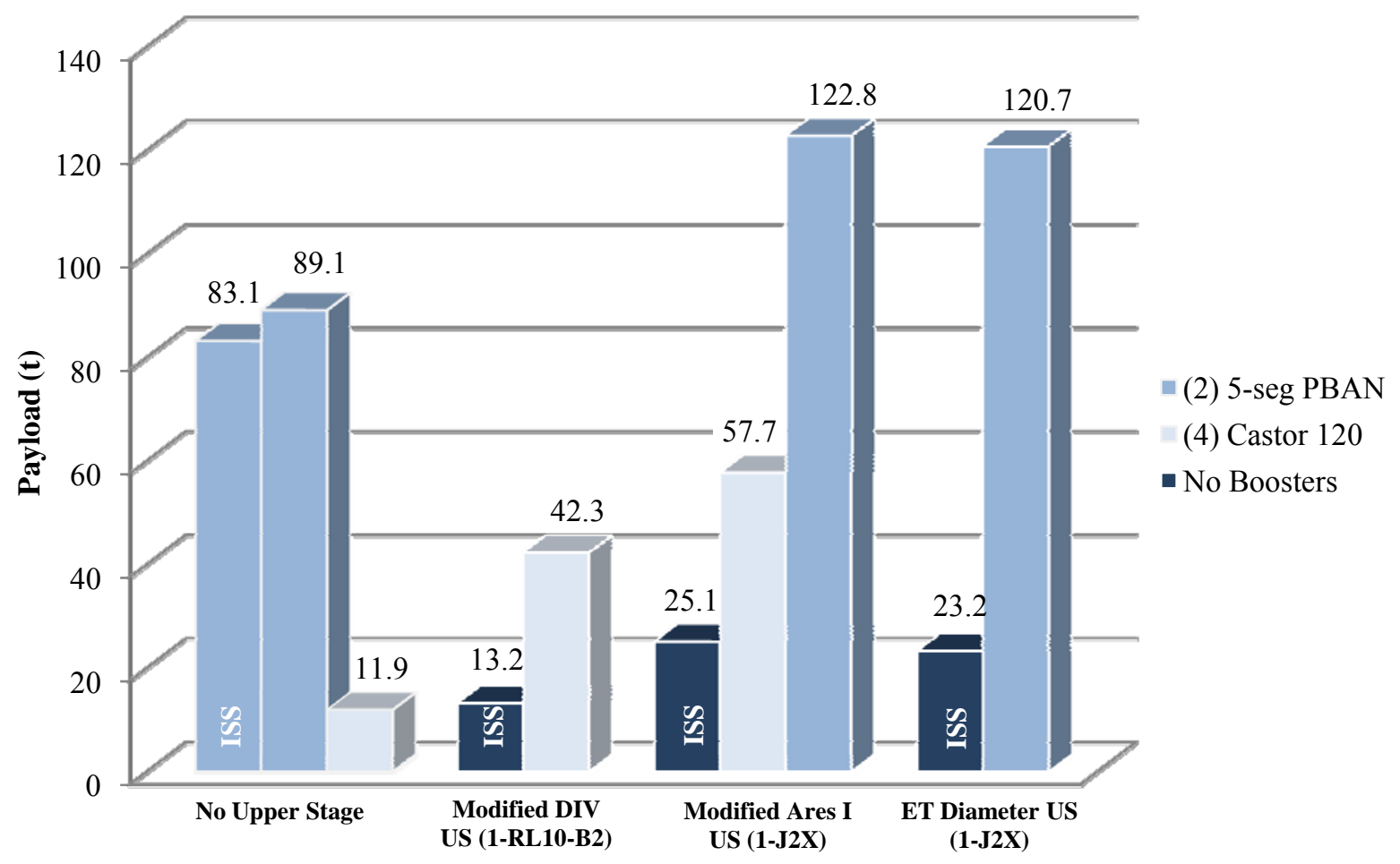

Figure 9. Payload capabilities with the common core element.

Figure 9 presents the resultant payload performances of the entire spectrum of study concepts, indicating a wide array of payload capabilities. The concepts with the highest payload capability are those that utilize the 5-segment SRB strapon boosters. The addition of the smaller, Castor-type solids improves the payload capability of the vehicle over the standalone core with the modified DIV and Ares I upper stages by approximately 30 t. The common core with 5 segment boosters can deliver a high amount of payload to orbit (nearly $90 \mathrm{t}$ ) without an upper stage. Adding an upper stage to this configuration increases the capability by $\approx 30 \mathrm{t}$.

Since the common core element was sized to accommodate configurations using the 5 segment SRBs, concepts not utilizing the large solid motor were at the disadvantage of having to lift a stage that was much larger than optimal for its particular design. Because these did not have the advantage of the high thrust impulse supplied by the 5 segment SRB's, propellant had to be offloaded from the full capacity of the common core element, ensuring the minimum 1.2 liftoff thrust to weight as set in the study's ground rules (Fig. 10). In POST this 1.2 thrust-to-weight is a constraint that must be held while the optimization scheme determines how to maximize the payload that can be delivered while offloading the right amount of propellant. Concepts with larger upper stage masses and higher payload capabilities required as much as $55.0 \%$ offload without boosters and a $26.4 \%$ offload with Castor-type boosters. Core offload was good in the sense that the concept had an acceptable, positive acceleration; however, core engine burn time is diminished causing a lower delta-velocity $(\mathrm{dV})$ at burnout, relative to non-offloaded concepts. 


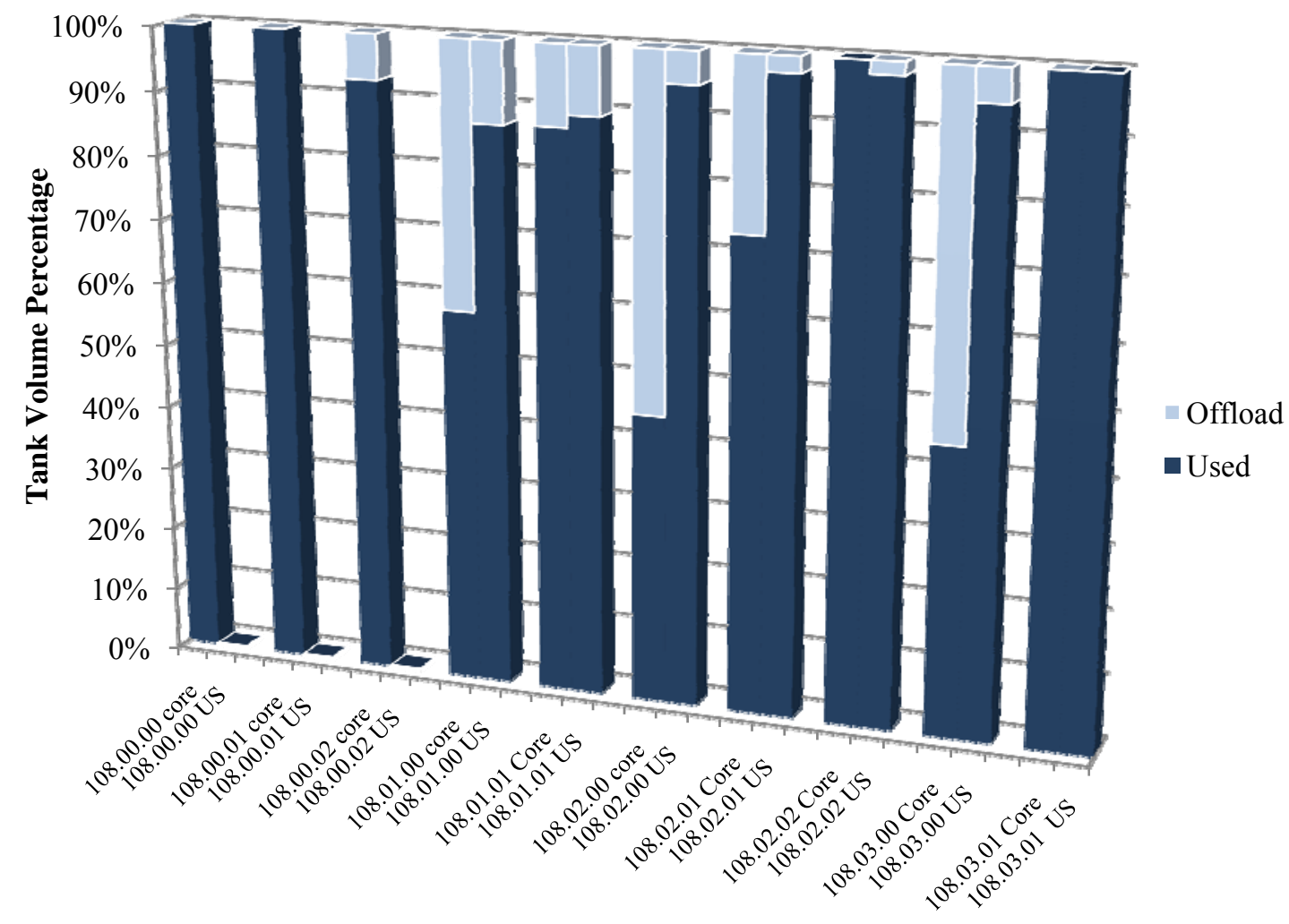

Figure 10. Concept vehicle propellant offload percentage.

Additionally, the upper stage propellant loads for each concept were optimized for maximum payload delivery to the given orbit. Typically this is found by optimizing the size of the upper stage, ensuring that the maximum payload is achieved when the upper stage propellant is depleted. This stage optimization was the method used on the vehicle featuring the ET diameter upper stage with 5-segment boosters; accordingly, that particular upper stage has zero offload. The vehicles with the Ares I and Delta IV upper stage are offloaded because these are fixed stages; the tank sizes are already established and required as much as $12.6 \%$ offload for payload optimization. In these cases POST determined how much propellant should be loaded to achieve the maximum payload. For concepts where both core and upper stages required offload, POST was allowed to determine both propellant loads to find the best delta velocity split to maximize payload while being constrained by the thrust-to-weight at liftoff and the stage dry masses.

\section{A. No Upper Stage}

The initial set in the concept matrix (108.00.0x) and first on the evolutionary path were concepts that utilized a core stage in combination with two different solid motor boosters. Such a starting point was logical from a developmental standpoint in that, given the 5-segment SRB's were available from Ares I, only the common core stage and shroud are needed. In the event that the 5-segment SRB's were not initially available, an attempt was made to quantify the performance of a smaller, Castor-type strap-on booster. Furthermore, given the same configuration, runs were made to quantify the performance delivery to an ISS transfer orbit of $-11 \mathrm{nmi}$ x $100 \mathrm{nmi} @$ $51.6^{\circ}$ versus a LEO delivery orbit of 30 x $130 \mathrm{nmi} @ 29^{\circ}$. Given the significant ISS delivery of $83.1 \mathrm{t}$, the concept was modeled with a cargo-carrying payload cylinder below the CEV/LAS combination to accommodate the added payload capability.

The high thrust and longer burn time of the 5-segment SRB, when compared to the Castor-type solid strap-on motors, rendered the payload performance of the latter-equipped concept insignificant. Even with the payload 
disparity (Fig. 11) and propellant offload, the liftoff thrust-to-weight are slightly in favor of the 5 -segment over the Castor-type equipped concept, $\approx 1.4$ and $\approx 1.2$ respectively; however, the maximum thrust-to-weight during booster burn, $\approx 2.9$ versus $\approx 1.6$, indicates the extreme advantage of the 5-segment. This can be attributed, not only to the $\approx 5.0 \mathrm{M} \mathrm{lbf}$ (total) advantage in thrust, but also to the 5-segment's burn time being $\approx 40 \mathrm{~s}$ longer than the Castor-type. Combining these allows the 5-segment equipped concept to achieve double the Castor-type equipped concept $\mathrm{dV}$ at booster separation. Heating rate on the shroud reaches limit levels $\approx 30 \mathrm{~s}$ sooner with the 5-segment, yielding earlier separation and reduction in inert mass.

As previously mentioned, two distinct missions were evaluated in this study. One was finding the maximum cargo capability to LEO and the other was determining if a CEV sized mass could be delivered to an ISS transfer orbit. This particular configuration, without an upper stage, was flown to both orbits so conclusions can be extended to the other configurations

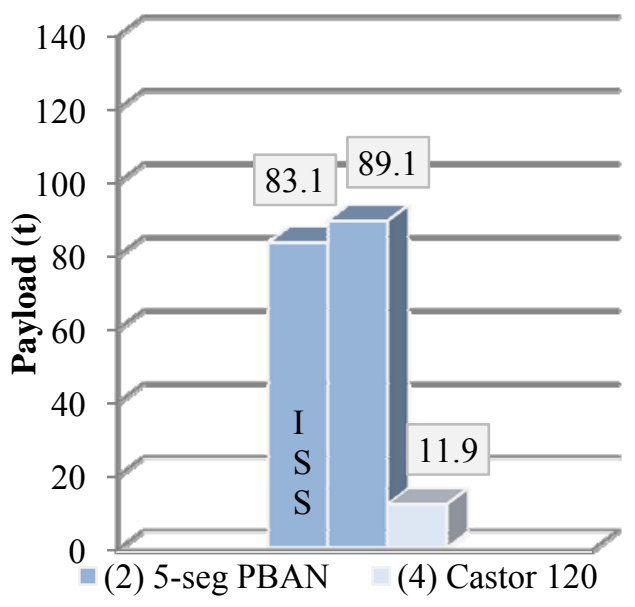

Figure 11. No upper stage with common core payload performance.

to determine a rough estimate of capability to the orbit not flown.

Comparing the trajectory profile of the 108.00 .00 vehicle and 108.00 .01 the two accelerate in a similar fashion. The pitch profile also optimizes to a similar set of rates for both missions. The only major differences are in the altitude plot, due to differing insertion points in the final orbit, Fig. 12, and a slight bump in the acceleration plot around $250 \mathrm{~s}$ because of shroud rather than LAS drop, Fig. 13.

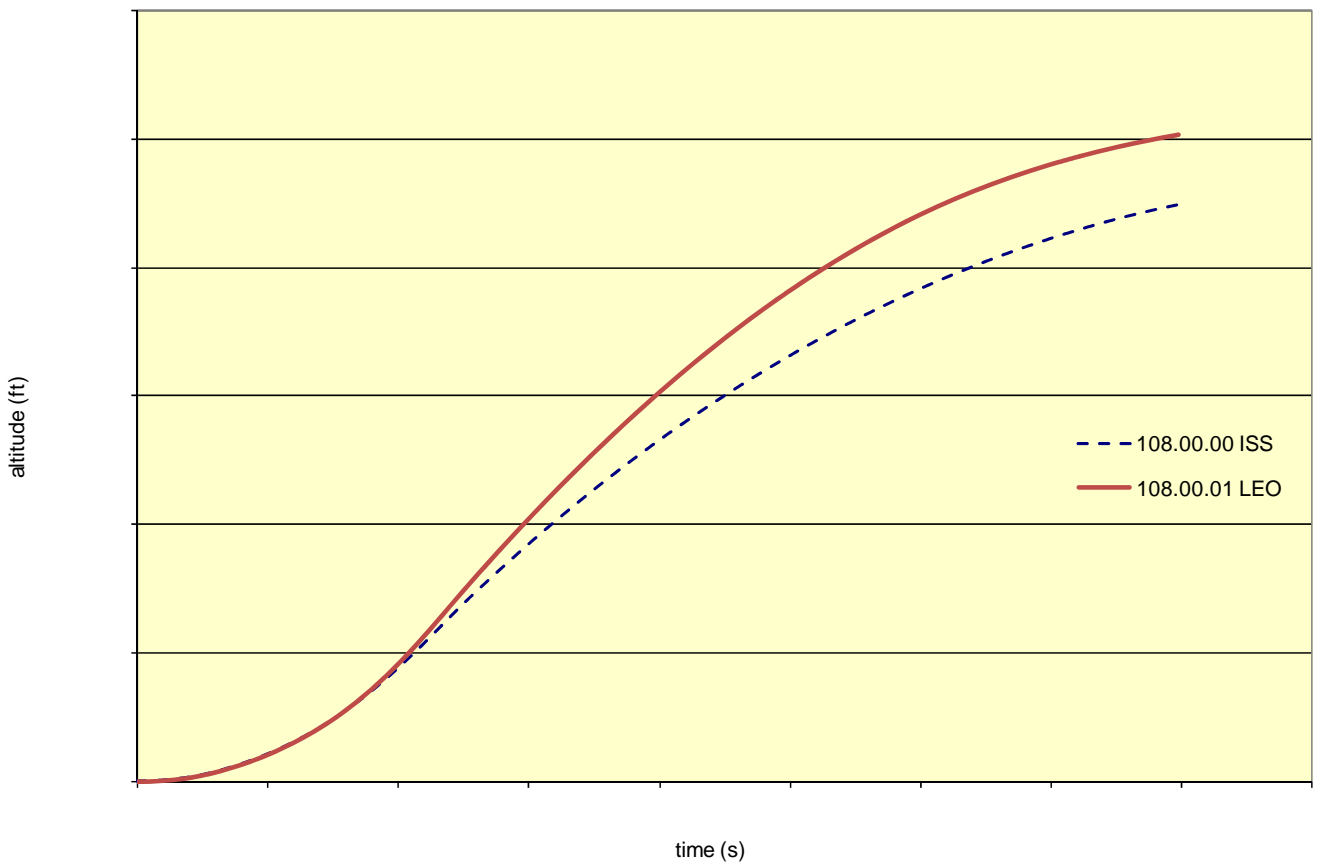

Figure 12. Altitude profile for concepts 108.00 .00 and 108.00.01. 


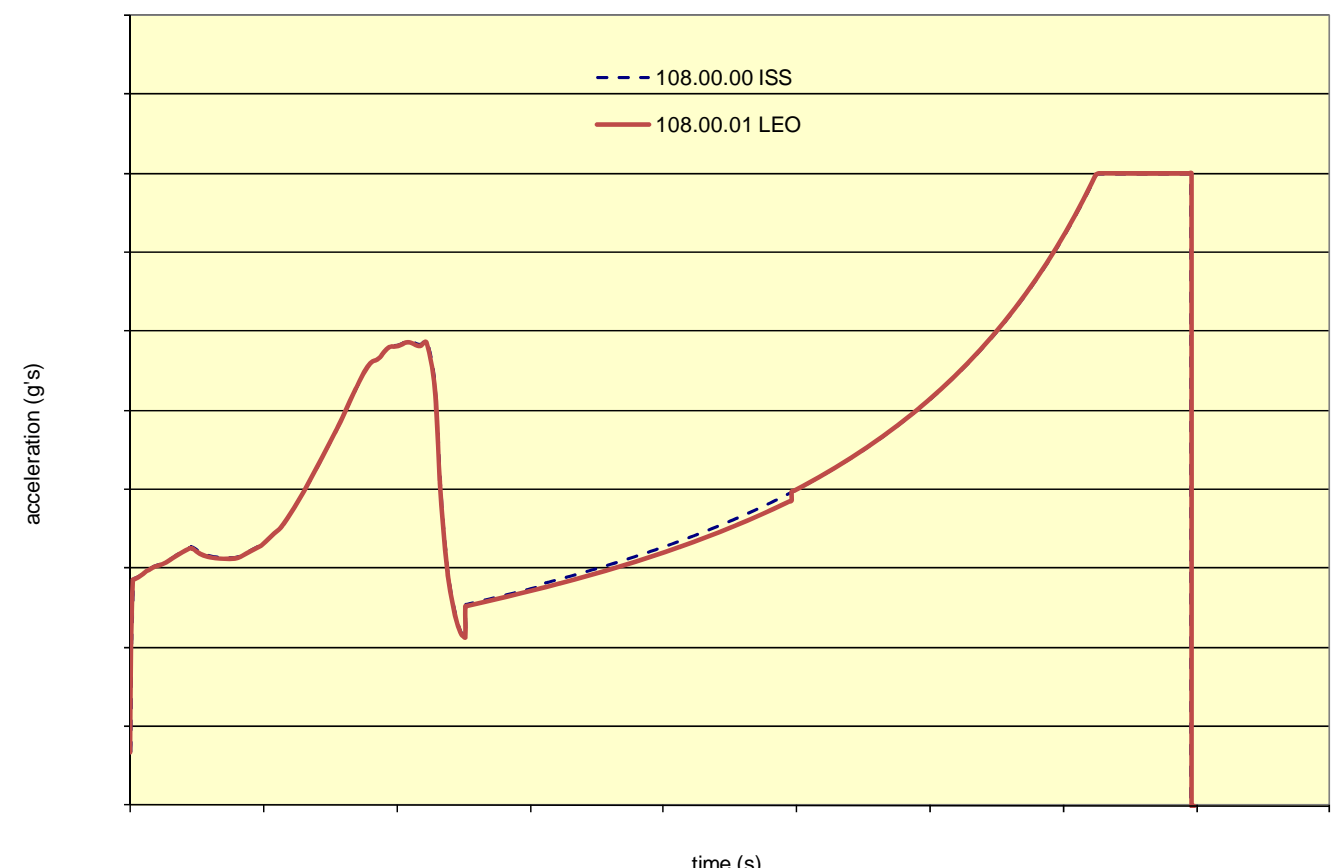

Figure 13. Acceleration profile for concepts 108.00 .00 and 108.00.01.

With the extent of similarity in vehicle design the payload delta between the configurations can be seen as solely dependent on inclination and orbital differences for the different missions. This does not mean that every vehicle flown to LEO will lose $6 \mathrm{t}$ if flown to ISS; instead, a delta in the percentages of delivered payload due to the evergy requirements for the two different orbits can be determined. Roughly calculated this delta payload is about $7 \%$, so vehicles reported as flown to ISS would get 7\% more payload if flown to LEO, likewise LEO missions would have $7 \%$ less payload if flown to ISS. This is not a rule for all launch vehicles, some underperforming upper stages may exhibit higher percent differences in payload but this $7 \%$ here can be seen as an adequate rule of thumb.

\section{B. Modified Delta IV Upper Stage}

The second set of concept vehicles (108.01.0x) paired an existing RL-10B2 DIV upper stage with the common core. As stated earlier, the DIV upper stage has some structural modifications as necessary to handle the loads environment imparted by the common core element and the higher payload capacity that what it typically sees.

Using such an existing stage to supplement the common core architecture fills a couple of niches; one, of bridging the gap between not having an upper stage to flying a stage under design such as the Ares I upper stage, and another, ultimately providing smaller payload capability (Fig. 14) without boosters potentially at lower development cost. The first concept was flown to an $-11 \mathrm{nmi} \times 100 \mathrm{nmi}$ ISS delivery orbit without the assistance of strap-on boosters and the second was flown to $30 \mathrm{nmi} \times 130 \mathrm{nmi}$ LEO delivery with four Castor-type boosters.

Several specific attributes of these concepts strongly contribute to the observed performance which, upon comparison to other concepts in the matrix, is quite poor. First and foremost, the core and upper stage are under thrusted. In order to maintain a liftoff thrust-to-weight $\geq 1.2$, each core in this series must undergo a propellant offload.

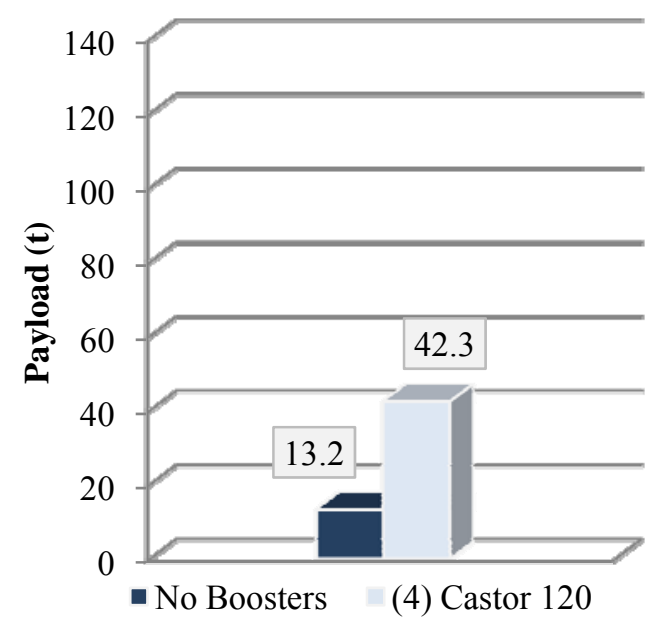

Figure 14. Modified DIV upper stage with common core performance. 
In both cases this offload is quite a significant amount; however, the concept featuring no boosters is affected most, having to be offloaded $\approx 42 \%$ compared to the Castor-type concept's $\approx 12 \%$. This offload in combination with the low upper stage mass and low payload relegate a throttle event upon the core stage. This is done to maintain acceleration to within acceptable limits. These are continuous throttle events with duration of $\approx 58 \mathrm{~s}$ without SRB's and $\approx 40 \mathrm{~s}$ with Castor-type boosters.

The low payload and high propellant offload indicate that the common core element modeled with a modified Delta IV upper stage is not a good option. Since the structures of the common core element have been designed to handle all the load scenarios from the total matrix of vehicles analyzed, they are extremely overdesigned for this application. The addition of 5-segment boosters would increase performance, but this configuration is a good example of the significant reduction in payload capability due to non-optimization in favor of commonality.

\section{Modified Ares I Upper Stage}

Continuing on the evolutionary path of the matrix, the third set of concepts using the common core element (108.02.0x) makes use of the proposed Ares I upper stage with the single J$2 \mathrm{X}$ configuration. This particular upper stage was flown three ways: without boosters to ISS, with Castor-type boosters to LEO, and with 5-segment boosters to LEO, illustrating a wide range of capability (Fig. 15). As with the previous set of analysis, flying to an ISS transfer orbit without boosters allowed for the capability of flying a crew or light cargo/resupply transport. In addition, flying the same upper stage with the two different boosters to the same LEO orbit allowed for a estimated delta payload to be established for the step change between Castor-type and 5segment SRB's.

In order to attain a liftoff thrust-to-weight $\geq$ 1.2 , the concept with no boosters required a $\approx 55 \%$ offload of core propellant. This contributes to the diminished performance by necessitating a

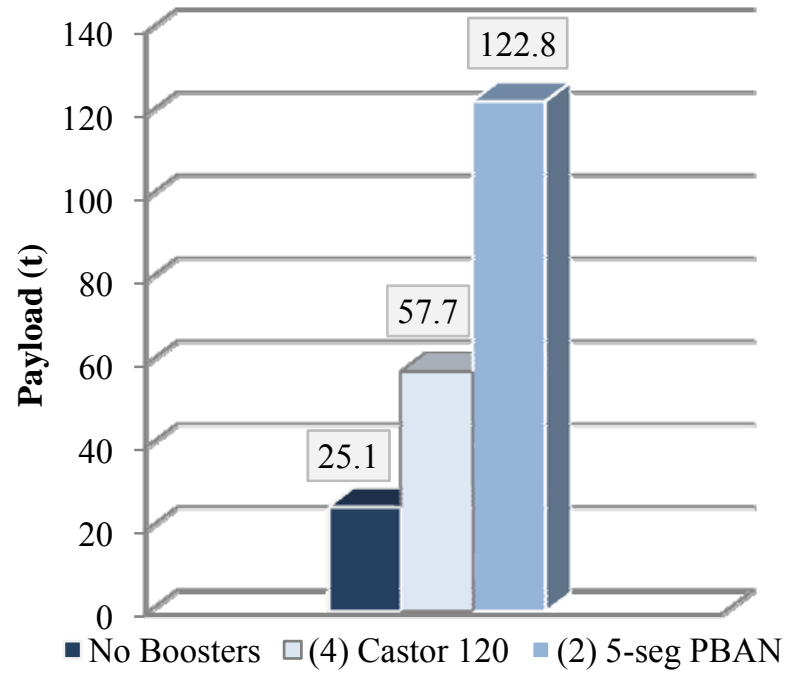

Figure 15. Modified Ares I upper stage with common core performance.

shortened burn time of $\approx 177 \mathrm{~s}$ with a $\mathrm{dV} \approx 13,100 \mathrm{fps}$ at core jettison. Still, given these detriments, this concept delivers $25.1 \mathrm{t}$ to an ISS orbit which is in line with current full size CEV mass. With the same upper stage element, stepping from the Castor-type to the 5-segment SRB's adds $\approx 65 \mathrm{t}$ to LEO payload. Due to the massive increase in liftoff thrust, the 5-segment core doesn't have to be offloaded and can utilize all $2.24 \mathrm{M} \mathrm{lbm}$ of propellant.

It is important to note that the shroud payload density of concept 108.02 .02 , at $11.3 \mathrm{lbm} / \mathrm{ft}^{3}$, is higher than typical historical densities. Originally, it was envisioned that the DIV upper stage and Ares upper stage concepts would carry the same shroud, in lieu of compounded development cost and schedule; however, the high performance of the Ares I with 5-segment SRB concept required a subsequent shroud sizing trade to characterize the extents of payload density feasibility. Such a partial study was undertaken in which the shrouds grew in diameter steps if $1.64 \mathrm{ft}(0.5 \mathrm{~m})$ and were stretched so that the entire vehicle length was capped at $390 \mathrm{ft}$. While the $6.5 \mathrm{~m}$ diameter shroud payload density is still on the high side of historical values, it cannot be precluded from the possibility of stage delivery, in which case the majority of payload would be high density propellant. 


\section{External Tank Diameter Upper Stage}

The final set of concept vehicles (108.03.0x) utilized an upper stage whose fuel tank has been sized to ET diameter. Since the performance step between the two different boosters was identified in the previous set, this one focused on the performance implications of using a common diameter between the core and upper stage and the potential of evolving a stage of this diameter into an Earth Departure Stage (EDS) for beyond LEO exploration missions. Similar to other concept families, the initial vehicle was flown without boosters to an ISS transfer orbit carrying a CEV/LAS combination. The performance capabilities of the ET diameter upper stage concepts are shown in Figure 16. Similar to the modified Ares I upper stage concept, the ET diameter upper stage concept is capable of lifting a CEV mass above that of the current full size Orion design. Furthermore, adding the 5-segment boosters delivers $120.7 \mathrm{t}$ to LEO which is, once again, comparable to the modified Ares I concept.

Due to the similarity between the modified Ares I upper stage and the ET diameter US, in reference to

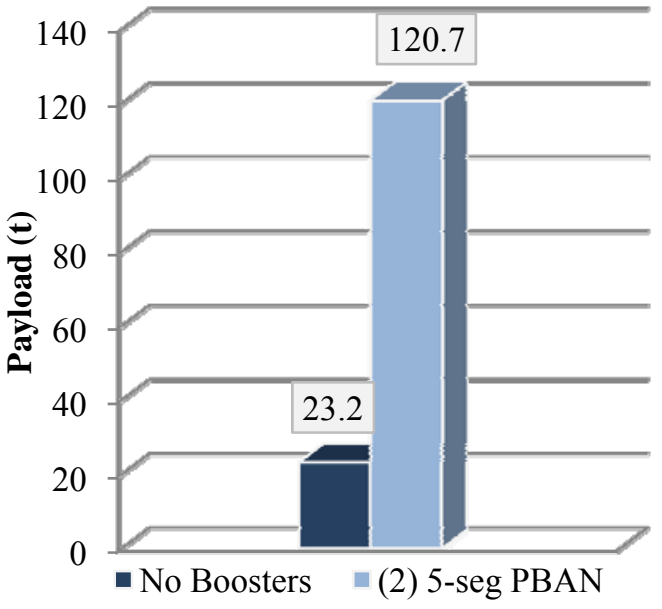

Figure 16. ET diameter upper stage with common core performance. optimized propellant loads and dry masses, it's no surprise that payload deliveries, thrust-to-weight ratios, and propellant offloads are numerically close. Incidentally, there are several points to consider when formulating conclusions. First is the payload density comparison. Recall that the payload density of the modified Ares I concept was extremely high relative to historical data. Since the upper stage in the current set of analysis is substantially larger in diameter, the optimized propellant loading for maximum payload delivery results in an overall shorter upper stage length. This enables the shroud to not only be wider in diameter without a hammerhead design, but allows for a larger payload envelope lengthwise. This larger diameter and larger shroud also have detriments being the interstage and shroud mass are much larger. If the modified Ares I concepts were sized to achieve a payload density identical to this concept, the final performance would be even more similar.

Also, in all practicality, a larger upper stage element would be envisioned for earth departure usage. Sizing for departure missions (TLI/LOR/various C3) would, in all likelihood, require growth of propellant tanks and all other associated, coincidental mass. Flying such a larger stage to LEO orbits would require substantial propellant offload and would sacrifice performance, more than likely lowering the given performance numbers; conversely, the stage would possess the capability to support a wider array of missions than any of the other representative upper stages presented in this study.

\section{E. ISS Missions}

When reviewing the data from the concepts for ISS missions, several comparisons can be drawn among the various upper stage pairings with the modular core and no strap-on boosters. One significant finding that can be observed is the low relative payload of the modified DIV upper stage. This large difference is driven primarily by the very low thrust; accordingly, lower thrust to weights at upper stage ignition resulted in a much higher loft in the ascent trajectory than what is typically seen in trajectories with high thrust upper stages, Fig. 17.

An interesting byproduct of the low RL-10B2 thrust is the percent of upper stage offload propellant required to maximize payload. The configuration with the Delta IV upper stage has $48 \%$ offload while the other two vehicles have a $55 \%$ offload. This lower percent offload meant there was more propellant in the core to burn causing the core to burn longer. However, the longer burn meant this core reached the acceleration limit and had to start throttling.

Typically throttling robs a vehicle of performance but in this case the continued burn of the 5 throttled RS-25E's were better than staging to the single RL-10B2. Also, the vehicle has only reached 200,000 $\mathrm{ft}$ at $200 \mathrm{~s}$ so the longer burn time mitigates the gravity losses. Higher thrust is usually the best way to overcome this deficit. The ideal delta velocity plot also shows why the offload percent is lower, the core needs to provide much more $\mathrm{dV}$ to make mission, Fig. 17. 


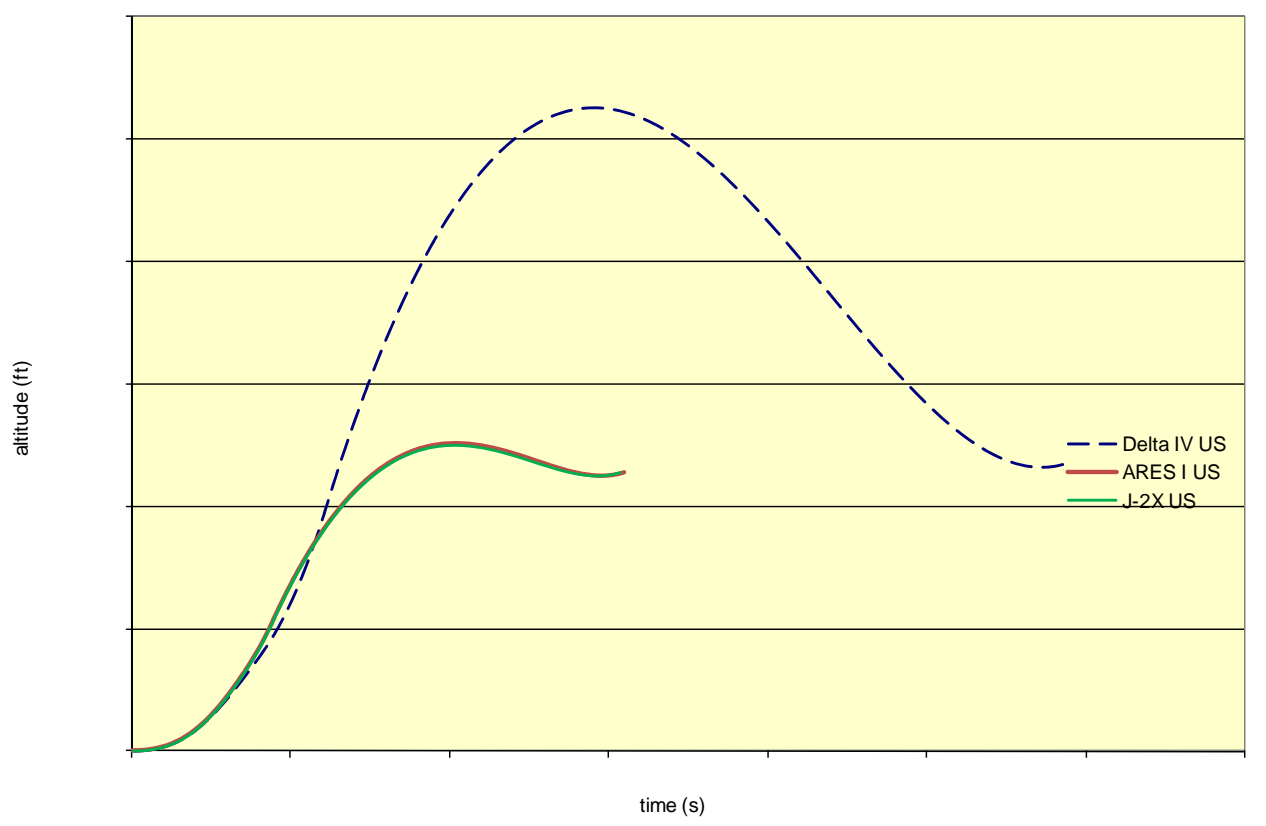

Figure 17. Altitude profiles for ISS missions with various upper stage elements.

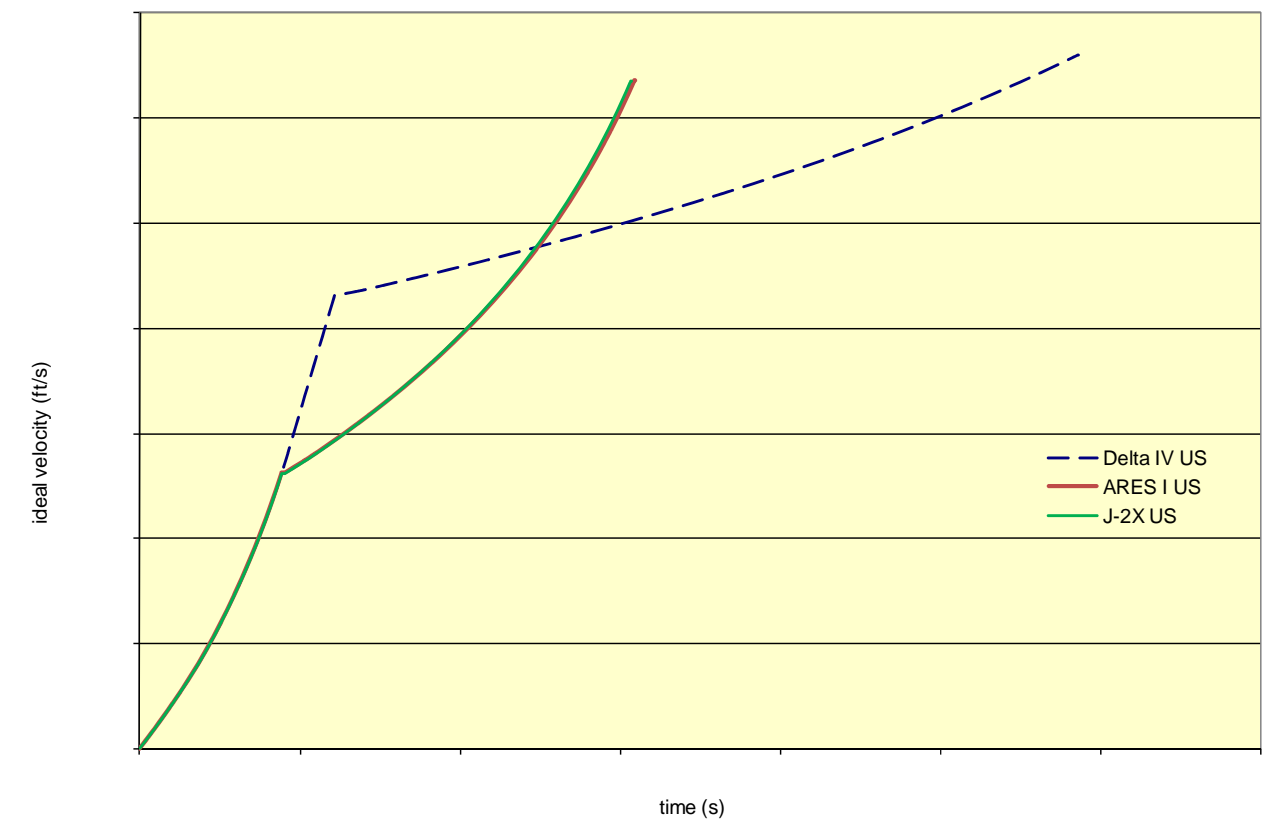

Figure 18. Ideal velocity for ISS missions with various upper stage elements.

As for comparisons among the Ares I upper stage and the ET diameter upper stage, both of these appear very similar from a trajectory standpoint. Both can hold similar propellant loads and have the same engine, so similar behavior in trajectory analysis is expected. It should be noted that the ET diameter stage built for this study does have a small percentage of offloaded propellant. This is because this stage was actually sized for the cargo LEO mission. The percent offload is due to the difference in the mission evaluated.

\section{F. Cargo Missions}

General trends are that 4 Castor 120-type boosters do not make up for 2 SRB's and some offload is required to accommodate the lower available thrust. SRB cases on the other hand require no offload since their integration was a leading design feature in creating the modular core. The same remarks made about the modified Delta IV upper 
stage under the ISS mission heading hold true here also. Figure 19 shows a similar loft, but not as highly a lofted trajectory as the ISS mission in Figure 17 The reduction in loft required for this trajectory can be attributed to the higher thrust provided by the strap on boosters and the longer burn time of the core. The higher thrust meant less core propellant offload, which increased core burn time and led to higher altitude at which staging occurred. The overall result is lower gravity losses affecting the vehicle.

As for cases utilizing SRB's the most noticeable trend is also one that has been previously mentioned. The Ares I upper stage and the ET diameter upper stage have almost identical trajectory profiles. This is best indicated by the ideal velocity curve, Fig. 20.

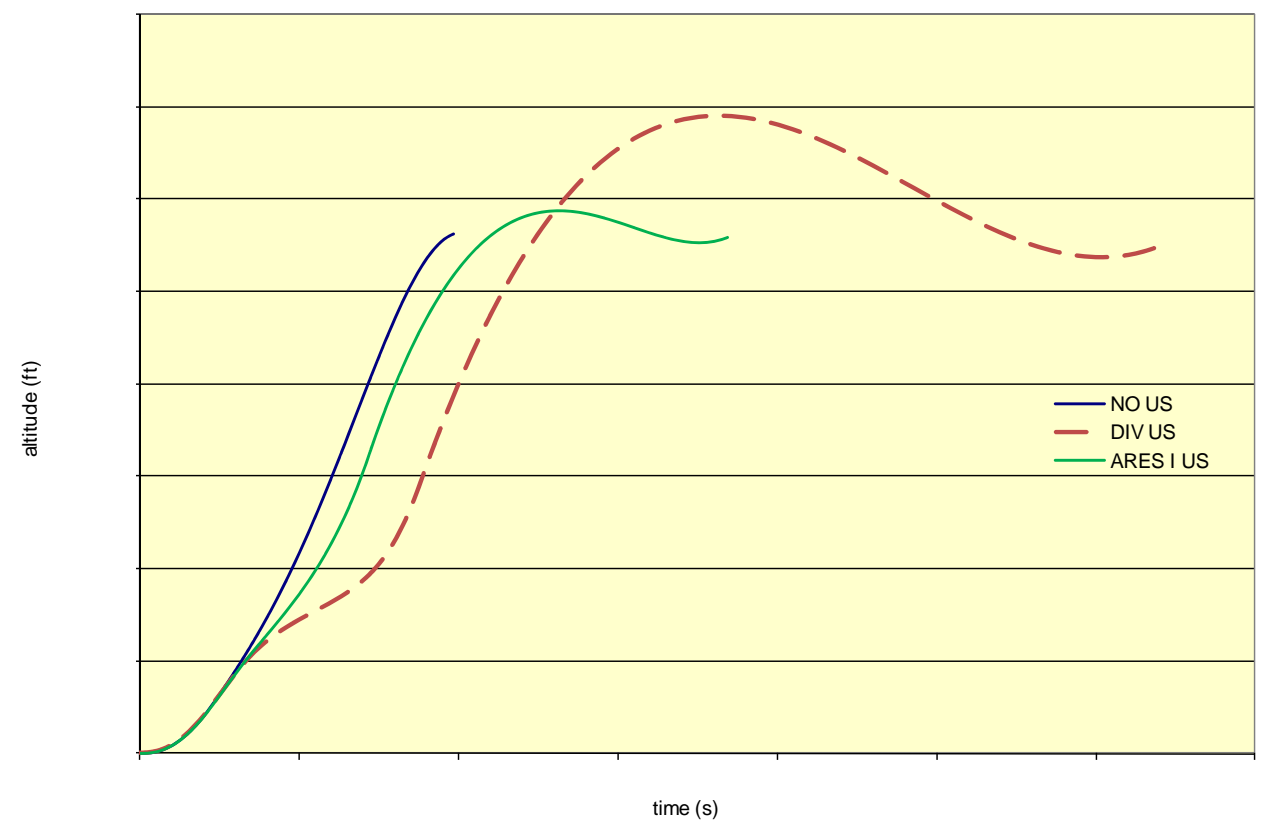

Figure 19. Altitude profile of LEO cargo missions with various US elements.

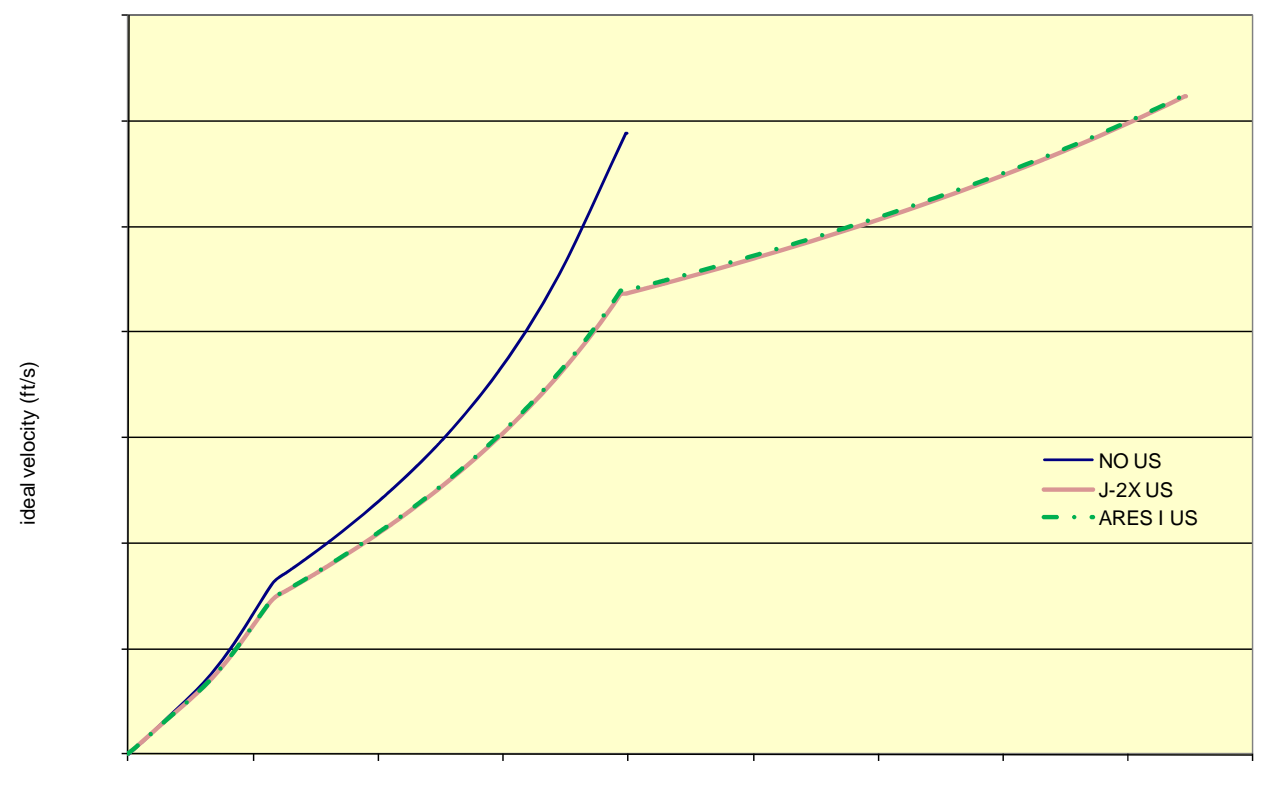

Figure 20. Ideal velocity for cargo missions with various US elements. 


\section{Conclusion}

The development of a launch vehicle architecture from a common core element can prove to be beneficial on a variety of levels. This approach provides for an evolutionary pathway of launch vehicle development that yields a wide array of performance capabilities while minimizing development costs, when used in conjunction with other existing or near existing vehicle component assets. Even though the later stages of the evolutionary path analyzed in this study, correspond with the highest performing concepts, the initial configurations displayed impressive up-front capability to both ISS and LEO orbits. Moreover, the premise of a partially deferred cost, stepped development is an attractive property of such launch vehicle design logic.

However, there are some drawbacks coincidental with this approach. A common core element has to be designed to accommodate the full spectrum of loads imparted by the upper stages, boosters, and payload masses that it will see in each vehicle application, thus the structural core mass will not be optimized for each concept and performance will be reduced in lieu of lower development cost and manufacturing complexity. Though not as significant as originally presumed, some common core concepts are structurally penalized more so than others. Concepts without upper stages as well as those not employing 5-segment boosters have significantly larger core masses than what they would be sized for if they were stand alone vehicle concepts. Concepts that have smaller diameter upper stages than the ET diameter core stage had to use a conical interstage. The additional lateral loads imparted from interstages with this geometry increased the structural masses in the forward section of the core stage. Similarly, the common core was designed to account for the pad and aerodynamic loads encountered with the 5segment boosters. Concepts not utilizing these particular boosters were structurally over designed. Another negative of this particular matrix surfaced after discovering the high payload densities of some shrouds. This discovery negated the principle of shroud commonality across upper stage families.

It must be understood that the intent of this study was not an investigation of the optimal vehicle configuration for the common element application. Continued and expanded studies would have to be performed in order to identify vehicle elements best suited for this type of function and with the desired balance of performance versus evolution. The highest, biggest impact levels of a comprehensive study would include: a variance of specific mission orbits and departure velocities, an array of core diameters, propellant types and engines along with various types of boosters, and targeted use of composite materials. Moreover, an integrated cost and reliability review would be fundamental in evaluating feasibility and truly exposing any inherent advantages involved with common element utilization. 


\section{References}

${ }^{1}$ Lynn, E., User's Manual - Integrated Rocket Sizing (INTROS) Program, Version 4.3, June 2009.

${ }^{2}$ Powell, R.W., Striepe, S.A.,Desai, P.N., Braun, R.D, Brauer, G.L., Cornick, D.E., Olson, D.W., Peterson, F.M., Stevenson, R., Utilization Manual-Program to Optimize Simulated Trajectories (POST), Volume 2, Version 5.2, Oct 1997. 